\title{
Glicerol não refinado na alimentação de bovinos de corte em confinamento
}

Italu Santos Silva ${ }^{a}$, Fabiano Almeida Vargas ${ }^{a}$, Arthur Felipe Diniz Magalhães ${ }^{a}$, Julia de Sousa Lima ${ }^{a}$, Jhonatan Lafaete Freitas Lourenço ${ }^{a}$, Letícia Oliveira Xavier ${ }^{a}$, Romário Mendes dos Santos ${ }^{a}$, Lorena Martins Oliveira ${ }^{a}$, Isabela Silva Fonseca ${ }^{a}$, Eduardo Rodrigues de Carvalho ${ }^{b}$

aGraduandos em Agronomia, Instituto Federal de Educação, Ciência e Tecnologia Goiano (Campus Iporá), Iporá, GO, Brasil. bProfessor de Ciência Animal, Instituto Federal de Educação, Ciência e Tecnologia Goiano (Campus Iporá), Iporá, GO, Brasil.

RESUMO A produção mundial de biodiesel tem crescido nos últimos anos com o intuito de diminuir a dependência do uso de combustíveis fósseis, fazendo com que o glicerol não refinado, o qual é um subproduto da indústria do biodiesel, também aumente a sua oferta e se torne uma opção viável como fonte de energia na substituição de alimentos energéticos tradicionais (cevada, milho e sorgo) em rações de bovinos de corte em confinamento. Objetivou-se neste trabalho de revisão abordar alguns aspectos sobre o potencial de uso do glicerol não refinado como ingrediente primário nas rações de bovinos de corte em confinamento. A compilação de vários artigos encontrados na literatura indicou que a substituição parcial de grãos e cereais pelo glicerol não refinado não afetou o desempenho animal, características da carcaça e qualidade da carne de bovinos de corte terminados em confinamento.

$$
\text { PALAVRAS-CHAVE biodiesel; desempenho; energia; ração; subproduto; substituição }
$$

Aceito 07 de setembro de 2019 Publicado online 14 de setembro de 2019

Cite este artigo: Silva IS et al. (2019) Glicerol não refinado na alimentação de bovinos de corte em confinamento. Multidisciplinary Reviews 2: e2019019, DOI: $10.29327 /$ multi.2019019

\section{Crude glycerol feeding to beef cattle in feedlot}

ABSTRACT The biodiesel production across the world has grown in recent years in order to reduce the dependence on the use of fossil fuels, causing crude glycerol, which is a byproduct of the biodiesel industry, also increase its supply and become a viable energy source in the substitution of traditional energy feeds (barley, corn, and sorghum) in rations fed to beef cattle finished in feedlot. The objective of this review work was to address some aspects of the potential use of crude glycerol as a primary ingredient in rations fed to beef cattle in feedlot. The data collection of several articles found in the literature has indicated that the partial substitution of grains and cereals with crude glycerol did not affect animal performance, carcass traits, and meat quality of beef cattle finished in feedlot.

KEYWORDS: biodiesel, byproduct, energy, performance, ration, substitution

\section{Introdução}

A população mundial vem crescendo nos últimos anos em ritmo desacelerado, mas a previsão para o ano de 2030 é de oito bilhões de pessoas no total (Department of Economic and Social Affairs of the United Nations 2017).

A fim de suprir carne bovina em quantidade e qualidade suficientes a essa população numerosa, é necessário o conhecimento sobre o desempenho de bovinos de corte terminados em confinamento que são alimentados com subprodutos agrícolas ou industriais, tais como o glicerol não refinado, o qual tem o potencial de substituir alimentos energéticos tradicionais utilizados em confinamentos (milho, sorgo, milheto, cevada, etc.). A diminuição de grãos na dieta de animais confinados poderá reduzir o custo da @ do boi e permitir que esses cereais sejam utilizados diretamente na alimentação humana nas regiões mais pobres do planeta.

Atualmente, o aumento na produção de biodiesel em todo o mundo em função da redução do uso de combustíveis fósseis tem gerado o aumento concomitante na oferta de glicerol não refinado, o qual não pode ser 
totalmente absorvido pelas indústrias química, farmacêutica e alimentícia após o processo de refino (Ayoub e Abdullah 2012), criando assim uma ótima oportunidade no uso desse subproduto como ingrediente primário nas dietas de bovinos de corte em confinamento.

Países como os Estados Unidos são dependentes basicamente do óleo de soja e da gordura animal para a produção de biodiesel, ao passo que o Brasil conta com mais opções de culturas oleaginosas (além da gordura animal), tais como a palma, o babaçu e o pinhão manso na Região Norte, a soja, o girassol e o amendoim nas Regiões Sul, Sudeste e Centro-Oeste, e a mamona como opção para a região Nordeste.

A produção de biodiesel no Brasil tem crescido e atingiu 3,8 milhões $\mathrm{m}^{3}$ no ano de 2016 (ANP 2017). Tal aumento se deve em função da adição compulsória de $8 \%(\mathrm{v} / \mathrm{v})$ de biodiesel no óleo diesel (B8) e também devido à maior diversidade de plantas oleaginosas utilizadas na fabricação do biodiesel, o que permite a instalação de indústrias em vários locais do país (ANP 2017). Objetivou-se com este trabalho de revisão abordar alguns aspectos sobre o potencial de uso do glicerol não refinado como ingrediente primário nas rações de bovinos de corte em confinamento.

\section{Propriedades químicas e processo de fabricação do glicerol não refinado}

O glicerol não refinado é um líquido viscoso, levemente adocicado, cuja fórmula molecular é $\mathrm{C}_{3} \mathrm{H}_{5}(\mathrm{OH})_{3}, \mathrm{massa}$ molar de 92,09 g/mol e densidade de 1,26 kg/L (Gerpen 2004). Por definição o glicerol não refinado é um álcool açucarado.

O biodiesel é produzido por uma reação de transesterificação que utiliza uma base catalisadora a qual reage com a gordura vegetal ou animal na formação de ésteres de ácidos graxos metílicos e etílicos, sendo o glicerol não refinado o subproduto desta reação (Figura 1).

No caso da produção de biodiesel à base de óleo de soja, reage-se a mesma quantidade de óleo com um álcool de cadeia curta (normalmente metanol ou também etanol dependendo das instalações industriais) na presença de um catalisador (hidróxido de sódio ou hidróxido de potássio) para a produção de biodiesel e glicerol não refinado (Gerpen 2004).

Para cada 100 g de óleo de soja que são utilizados no início da reação, são obtidos 12,25 g de glicerol não refinado (Thompson e He 2006). O biodiesel é então separado do glicerol não refinado por gravidade ou centrifugação (Gerpen 2004).<smiles>[R]C(=O)OCC(I)C(I)OC([R1])=O</smiles>

triglyceride methanol mixture of fatty esters glycerol

Triglicerídeo Metanol Biodiesel Glicerol não refinado

Figura 1 Reação de transesterificação para produção de biodiesel. (Gerpen 2004)

De acordo com a US FDA (2006), o glicerol é classificado como seguro para uso na alimentação animal, apesar do glicerol definido nessa classificação ser refinado e historicamente produzido nas indústrias de sabões. Por outro lado, 
o glicerol não refinado contém alguns contaminantes (água, sais e metanol), dos quais o metanol é o mais preocupante, sendo que a US FDA (2006) ressaltou que o glicerol proveniente da produção de biodiesel deve conter no máximo 150 mg de metanol por kg de glicerol, sendo que níveis acima desse limite são inapropriados para o uso na alimentação animal devido à redução no consumo.

\section{Histórico do uso do glicerol em ruminantes}

Inicialmente o glicerol foi utilizado como precursor gluconeogênico no tratamento da cetose na década de 50 . À época, sabia-se que o glicerol era um metabólito natural que é sintetizado na formação de tecido adiposo e oxidado quando esse mesmo tecido é catabolizado (Johnson 1955). O mesmo autor reportou que quando vacas receberam o glicerol na forma oral, misturado ao concentrado ou diretamente no rúmen através da cânula ruminal, não houve nenhuma reação adversa nos animais, a não ser a redução no consumo de matéria seca devido ao alto conteúdo de energia do glicerol. Assim, concluiu-se que o glicerol era eficiente no tratamento de cetose como precursor gluconeogênico, porém seu uso não foi viabilizado à época devido ao alto custo de produção (Johnson 1955).

A avaliação do glicerol para tratamento da cetose foi posteriormente investigada na década de 70, quando Fisher et al (1971) adicionaram 3,3\% de glicerol ou propileno glicol ao concentrado de vacas leiteiras em lactação. O consumo do glicerol e propileno glicol foram de 472 e $376 \mathrm{~g} /$ dia, respectivamente. O aumento do consumo de glicerol em relação ao propileno glicol ocorreu em função do maior consumo de concentrado das vacas suplementadas com glicerol (14,3 $\mathrm{kg} / \mathrm{dia}$ ) comparado às vacas suplementadas com propileno glicol (11,4 kg/dia). Nesse mesmo estudo, não houve efeito de tratamento sobre o consumo de feno, produção e composição de leite, balanço de energia, concentração de glucose no sangue, $\mathrm{pH}$ ruminal e concentrações de acetato e propionato no rúmen, porém as vacas suplementadas com glicerol aumentaram a concentração de butirato no rúmen e de ácido $\beta$-hidroxibutírico no sangue (Fisher et al 1971), o que pode ser considerado um efeito negativo no uso do glicerol devido ao papel exercido pelo butirato na formação de corpos cetônicos (Bergman 1990), além de que o aumento na concentração de $\beta$-hidroxibutírico no sangue pode vir acompanhado pela redução no consumo de matéria seca e reações metabólicas indesejáveis (Carvalho et al 2011).

Posteriormente, o glicerol foi reexaminado quanto à sua máxima dose tolerável e também no tratamento clínico de cetose ou acetonemia. A administração de um, dois ou três litros de glicerol via tubo esofágico em vacas não lactantes aumentou a concentração de glucose no sangue em 16, 20 e 25\% após 30 minutos, comparado aos valores prétratamentos, e permaneceram elevados por oito horas, voltando aos níveis antes dos tratamentos após 24 horas. Duas das três vacas que receberam três litros se mostraram cambaleantes, tendo retornado à sua condição normal dentro de quatro horas (Goff e Horst 2001).

Em relação ao tratamento de acetonemia clínica, duas vacas lactantes previamente tratadas por dois dias com glucose intravenosa apresentando pouca melhora receberam um litro de glicerol. Nos dois animais o nível de corpos cetônicos na urina foi reduzido a traços após 24 horas e a produção de leite foi aumentada entre 1,8 a 2,7 kg/dia. Além disso, a concentração de glucose no sangue em uma das vacas aumentou de 48 para $75 \mathrm{mg} / \mathrm{dL} 30$ minutos após a ingestão de glicerol e para $109 \mathrm{mg} / \mathrm{dL}$ cinco horas pós-tratamento, enquanto que na outra vaca a concentração de glucose no sangue permaneceu estável durante quatro horas pós-tratamento, quando então aumentou de 48 para 74 $\mathrm{mg} / \mathrm{dL}$ e reduziu para $64 \mathrm{mg} / \mathrm{dL}$ oito horas pós-tratamento (Goff e Horst 2001).

\section{Metabolismo do glicerol no rúmen}

No rúmen o glicerol é convertido a ácidos graxos de cadeia curta ou existe a hipótese de ser absorvido diretamente pelo epitélio ruminal. Trabalhos mais antigos reportaram que o glicerol foi totalmente convertido a propionato (Johns 1953; Garton et al 1961), sendo posteriormente confirmado por Kijora et al (1998). Outros autores reportaram aumento na proporção molar de propionato e redução de acetato no rúmen (Rémond et al 1993; Wang et al 2009; Carvalho et al 2011; Ramos e Kerley 2012; Bartoň et al 2013).

Conforme descrito anteriormente, existe a hipótese de o glicerol ser absorvido diretamente pelo epitélio ruminal baseado nos resultados obtidos por Rémond et al (1993), em que dos 0,24 kg/dia administrados diretamente no rúmen 
via cânula, 0,032 kg foram encontrados no abomaso, 0,105 kg foram fermentados no rúmen e 0,103 kg foram absorvidos diretamente através da parede do rúmen. Em concordância com esses autores, Kijora et al (1998) reportaram que somente $0,75 \%$ dos $0,2 \mathrm{~kg}$ de glicerol colocados diretamente no rúmen chegaram ao duodeno, e que o aumento da concentração de glicerol no sangue em até três vezes, comparado às amostras dos animais alimentados com a dieta controle, sugerem que o epitélio ruminal apresenta capacidade de absorção direta do glicerol.

A partir dos resultados reportados acima, infere-se que o glicerol age como precursor gluconeogênico no fígado principalmente devido ao aumento na proporção molar de propionato no rúmen. Portanto, a inclusão desse subproduto industrial na dieta de bovinos de corte em confinamento pode trazer benefícios no status energético dos animais.

\section{Desempenho de bovinos de corte em confinamento alimentados com glicerol não refinado}

Há um número considerável de estudos na literatura reportando a substituição parcial do glicerol não refinado por alimentos energéticos tradicionais, tais como o grão de cevada (Mach et al 2009; Bartoň et al 2013; Egea et al 2014), milho grão (Ramos e Kerley 2012; van Cleef et al 2014; Eiras et al 2014), milho floculado (Parsons et al 2009; Hales et al 2013; Buttrey et al 2015) e sorgo grão (Dias et al 2019).

A compilação resumida dos trabalhos citados acima se encontra no Quadro 1, em que, de forma geral, percebese que a substituição parcial de grãos e cereais pelo glicerol não refinado em níveis que variaram desde 2 até $30 \%$ do total da matéria seca da ração para bovinos de corte em confinamento de diferentes categorias (bezerros, novilhas e bois) e grupos genéticos não comprometeu o consumo de matéria seca, peso corporal final, ganho de peso diário, características da carcaça e qualidade da carne bovina.

\section{Considerações Finais}

O glicerol não refinado pode ser incluído com segurança na estratégia nutricional de bovinos de corte em confinamento em níveis que variam de 2 a 30\% do total da matéria seca da ração, devido principalmente ao seu alto conteúdo energético.

Devido à sua característica viscosa e aglutinante, o glicerol não refinado deve ser misturado com o volumoso da ração para proporcionar a sua completa homogeneização. Caso seja misturado com os alimentos concentrados, haverá a possibilidade da formação de grânulos de tamanho variado, facilitando a segregação no comedouro e aumentando a chance do consumo seletivo dos animais.

É importante conhecer a concentração de metanol (máximo de $150 \mathrm{mg} / \mathrm{kg}$ de glicerol não refinado) para evitar efeitos adversos no consumo de matéria seca total da ração.

A utilização em larga escala do glicerol não refinado como ingrediente primário em rações para bovinos de corte depende de alguns fatores, tais como a distância entre as indústrias de biodiesel e os confinamentos (o que irá impactar no preço do frete), logística de transporte e armazenamento do glicerol não refinado na propriedade rural por se tratar de alimento viscoso, e principalmente do preço do grão que irá ser substituído na ração como balizador do preço do glicerol não refinado.

\section{Referências}

Agência Nacional do Petróleo, Gás Natural e Biocombustíveis (ANP) 2017 Produção e fornecimento de biocombustíveis, Rio de Janeiro. On-line. Disponível em: <http://www.anp.gov.br/wwwanp/images/DADOS_ESTATISTICOS/Producao_biodiesel/Producaode-Biodiesel-m3.x|s>

Ayoub M, Abdullah AZ (2012) Critical review on the current scenario and significance of crude glycerol resulting from biodiesel industry towards more sustainable renewable energy industry. Renewable and Sustainable Energy Reviews. doi: 10.1016/j.rser.2012.01.054

Bartoň L, Bureš D, Homolka P, Jančík F, Marounek M, Řehák D (2013) Effects of long-term feeding of crude glycerine on performance, carcass traits, meat quality, and blood and rumen metabolites of finishing bulls. Livestock Science. doi: 10.1016/j.livsci.2013.04.010 
Bergman EN (1990) Energy contributions of volatile fatty acids from the gastrointestinal tract in various species. Physiological Reviews 70:567-590.

Buttrey EK, Luebbe MK, McCollum III FT, Cole NA, MacDonald JC, Hales KE (2015) Effects of glycerin concentration in steam-flaked corn-based diets with supplemental yellow grease on performance and carcass characteristics of finishing beef steers. Journal of Animal Science. doi: 10.2527/jas2015-9138

Carvalho ER, Schmelz-Roberts NS, White HM, Doane PH, Donkin SS (2011) Replacing corn with glycerol in diets for transition dairy cows. Journal of Dairy Science. doi: 10.3168/jds.2010-3581

van Cleef EHCB, Ezequiel JMB, D’Aurea AP, Fávaro VR, Sancanari JBD (2014) Crude glycerin in diets for feedlot Nellore cattle. Revista Brasileira de Zootecnia. doi: 10.1590/S1516-35982014000200006

Department of Economic and Social Affairs of the United Nations 2017, World Population Prospects. The 2017 Revision. On-line. Disponível em: <https://esa.un.org/unpd/wpp/Publications/Files/WPP2017_KeyFindings.pdf>.

Dias KM, Santos RT, Rodrigues MS, Claudio FL, Calgaro Junior G, Alves EM, Paim T, Carvalho ER (2019) Substituting sorghum grain with crude glycerol in diets for beef cattle. Archivos de Zootecnia. doi: 10.21071/az.v68i261

Egea M, Linares MB, Garrido MD, Villodre C, Madrid J, Orengo J, Martínez S, Hernández S (2014) Crude glycerin inclusion in Limousin bull diets: animal performance, carcass characteristics and meat quality. Meat Science. doi: 10.1016/j.meatsci.2014.06.034

Eiras CE, Barbosa LP, Marques JA, Araújo FL, Lima BS, Zawadzki F, Perotto D, Prado IN (2014) Glycerine levels in the diets of crossbred bulls finished in feedlot: apparent digestibility, feed intake and animal performance. Animal Feed Science and Technology. doi: 10.1016/j.anifeedsci.2014.07.004

Fisher L, Erfle JD, Sauer FD (1971) Preliminary evaluation of the addition of glucogenic materials to the rations of lactating cows. Canadian Journal of Animal Science 51:721-727.

Garton GA, Lough AK, Vioque E (1961) Glyceride hydrolysis and glycerol fermentation by sheep rumen contents. Journal of General Microbiology 25:215-225.

Gerpen JV (2004) Biodiesel processing and production. Fuel Processing Technology. doi: 10.1016/j.fuproc.2004.11.005

Goff JP, Horst RL (2001) Oral glycerol as an aid in the treatment of ketosis/fatty liver complex. Journal of Dairy Science 84:153.

Hales KE, Bondurant RG, Luebbe MK, Cole NA, MacDonald JC (2013) Effects of crude glycerin in steam-flaked corn-based diets fed to growing feed cattle. Journal of Animal Science. doi: 10.2527/jas2012-5944

Johns AT (1953) Fermentation of glycerol in the rumen of sheep. New Zealand Journal of Science and Technology 35:262-269.

Johnson RB (1955) The treatment of ketosis with glycerol and propylene glycol. Cornell Veterinarian 44:6-21.

Kijora C, Bergner H, Götz KP, Bartelet J, Szakács J, Sommer A (1998) Research note: investigation on the metabolism of glycerol in the rumen of bulls. Archives of Animal Nutrition 51:341-348.

Mach N, Bach A, Devant M (2009) Effects of crude glycerin supplementation on performance and meat quality of Holstein bulls fed high-concentrate diets. Journal of Animal Science. doi: 10.2527/jas.2008-0987

Parsons GL, Shelor MK, Drouillard JS (2009) Performance and carcass traits of finishing heifers fed crude glycerin. Journal of Animal Science. doi: 10.2527/jas.2008-1053

Ramos MH, Kerley MS (2012) Effect of dietary crude glycerol level on ruminal fermentation in continuous culture and growth performance of beef calves. Journal of Animal Science. doi: 10.2527/jas.2011-4099

Rémond B, Souday E, Jouany JP (1993) In vitro and in vivo fermentation of glycerol by rumen microbes. Animal Feed Science and Technology 41:121-132.

Thompson JC, He BB (2006) Characterization of crude glycerol from biodiesel production from multiple feedstocks. Applied Engineering in Agriculture 22:261-265.

U.S. Food \& Drug Administration (FDA) 2006, Code of Federal Regulations, 21 CFR 582.1320, Title 21, vol. 6, 21CFR582.1320, 2006. On-line. Disponível em: <http://edocket.access.gpo.gov/cfr_2002/aprqtr/21cfr582.1320.htm>

Wang C, Liu Q, Huo WJ, Yang WZ, Dong KH, Huang YX, Guo G (2009) Effects of glycerol on rumen fermentation, urinary excretion of purine derivatives and feed digestibility in steers. Livestock Science. doi: 10.1016/j.livsci.2008.05.010 
Quadro 1 Compilação de alguns experimentos que avaliaram o uso do glicerol não refinado em rações para bovinos de corte em confinamento.

\begin{tabular}{|c|c|c|c|}
\hline Autores & $\begin{array}{c}\text { Caracterização dos } \\
\text { animais }\end{array}$ & Tratamentos & Resultados \\
\hline $\begin{array}{l}\text { Mach et al } \\
\text { (2009) }\end{array}$ & $\begin{array}{l}48 \text { bois Holandeses com } \\
\text { PC inicial médio }=335 \pm \\
8,6 \mathrm{~kg} \text { e idade inicial } \\
\text { média }=9 \pm 0,42 \text { meses. } \\
12 \text { animais/tratamento. } \\
\text { Período experimental } \\
\text { de } 91 \text { dias. }\end{array}$ & $\begin{array}{l}\text { Substituição parcial do grão de cevada } \\
\text { pelo glicerol não refinado. Foram } \\
\text { avaliadas } 4 \text { dietas: controle ( } 32,7 \% \text { de } \\
\text { cevada e } 0 \% \text { de glicerol), } 4 \% \text { ( } 24,5 \% \text { de } \\
\text { cevada e } 4,4 \% \text { de glicerol), } 8 \% \text { ( } 15,5 \% \text { de } \\
\text { cevada e } 8,7 \% \text { de glicerol) e } 12 \%(9,1 \% \text { de } \\
\text { cevada e } 12,1 \% \text { de glicerol). }\end{array}$ & $\begin{array}{l}\text { As variáveis de desempenho animal } \\
\text { (CMS, PC final, GPD e eficiência } \\
\text { alimentar), características da } \\
\text { carcaça e qualidade da carne não } \\
\text { foram influenciadas ( } P>0,05) \text { pelos } \\
\text { níveis de glicerol na dieta. Os } \\
\text { autores indicaram a inclusão de } \\
12 \% \text { de glicerol na ração sem } \\
\text { prejuízos ao desempenho animal. }\end{array}$ \\
\hline $\begin{array}{l}\text { Parsons et al } \\
\text { (2009) }\end{array}$ & $\begin{array}{l}373 \text { novilhas mestiças } \\
\text { com PC inicial médio = } \\
421,6 \pm 28,9 \mathrm{~kg} \text {. O } \\
\text { período experimental } \\
\text { foi de } 85 \text { dias. }\end{array}$ & $\begin{array}{l}\text { Substituição parcial do milho floculado } \\
\text { pelo glicerol não refinado. Foram } \\
\text { avaliadas seis dietas: controle }(82,6 \% \text { de } \\
\text { milho floculado e } 0 \% \text { de glicerol), } 2 \% \\
(80,2 \% \text { de milho floculado e } 2 \% \text { de } \\
\text { glicerol), } 4 \% \text { ( } 77,8 \% \text { de milho floculado e } \\
4 \% \text { de glicerol), } 8 \% \text { ( } 73 \% \text { de milho } \\
\text { floculado e } 8 \% \text { de glicerol), } 12 \% \text { ( } 68,2 \% \text { de } \\
\text { milho floculado e } 12 \% \text { de glicerol) e } 16 \% \\
\text { ( } 63,4 \% \text { de milho floculado e } 16 \% \text { de } \\
\text { glicerol). }\end{array}$ & $\begin{array}{l}\text { Os parâmetros de desempenho } \\
\text { animal (CMS, PC final, GPD e } \\
\text { eficiência alimentar) e peso da } \\
\text { carcaça quente tiveram redução } \\
\text { linear }(\mathrm{P}<0,05) \text { ou efeito quadrático } \\
\text { ( } \mathrm{P}<0,05) \text { com o aumento do glicerol } \\
\text { na dieta. A área do músculo } \\
\text { Logissimus dorsi, índice de } \\
\text { marmoreio na carne e EGS tiveram } \\
\text { redução linear ( } P<0,05) \text { com o } \\
\text { aumento do glicerol na ração. Os } \\
\text { autores recomendaram o nível } \\
\text { máximo de } 8 \% \text { de glicerol como } \\
\text { substituto parcial do milho } \\
\text { floculado. }\end{array}$ \\
\hline $\begin{array}{l}\text { Ramos e Kerley } \\
\text { (2012) }\end{array}$ & $\begin{array}{l}72 \text { bezerros mestiços } \\
\text { com } \mathrm{PC} \text { inicial médio }= \\
312 \pm 12,7 \mathrm{~kg} \text { no } \\
\text { Experimento } 1 \text { durante } \\
150 \text { dias e } 100 \text { bezerros } \\
\text { mestiços com } \mathrm{PC} \text { inicial } \\
\text { médio }=357 \pm 9,3 \mathrm{~kg} \text { no } \\
\text { Experimento } 2 \text { durante } \\
135 \text { dias. }\end{array}$ & $\begin{array}{l}\text { Substituição parcial do milho grão pelo } \\
\text { glicerol não refinado. Foram avaliadas } \\
\text { quatro dietas no Experimento } 1 \text { : controle } \\
\text { ( } 79 \% \text { de milho grão e } 0 \% \text { de glicerol), } 5 \% \\
\text { ( } 74 \% \text { de milho grão e } 5 \% \text { de glicerol), } 10 \% \\
\text { ( } 67 \% \text { de milho grão e } 10 \% \text { de glicerol) e } \\
20 \% \text { ( } 55 \% \text { de milho grão e } 20 \% \text { de } \\
\text { glicerol). Foram avaliadas cinco dietas no } \\
\text { Experimento } 2 \text { : controle }(86,9 \% \text { de milho } \\
\text { grão e } 0 \% \text { de glicerol), } 5 \% \text { ( } 81,9 \% \text { de milho } \\
\text { grão e } 5 \% \text { de glicerol), } 10 \% \text { ( } 76,9 \% \text { de } \\
\text { milho grão e } 10 \% \text { de glicerol), } 12,5 \% \\
\text { ( } 74,4 \% \text { de milho grão e } 12,5 \% \text { de glicerol) } \\
\text { e } 15 \% \text { ( } 71,9 \% \text { de milho grão e } 15 \% \text { de } \\
\text { glicerol). }\end{array}$ & $\begin{array}{l}\text { Experimento 1: redução linear } \\
(P<0,05) \text { no } C M S \text { com o aumento do } \\
\text { glicerol na dieta e efeito quadrático } \\
(P<0,05) \text { sobre o GPD e eficiência } \\
\text { alimentar, sendo o nível de } 10 \% \text { de } \\
\text { glicerol o que apresentou os } \\
\text { melhores resultados. No } \\
\text { Experimento } 2 \text { as variáveis de } \\
\text { desempenho animal não foram } \\
\text { alteradas ( } P>0,05) \text { pelos níveis de } \\
\text { glicerol na ração. Os autores } \\
\text { reportaram que o glicerol não } \\
\text { refinado pode substituir o milho } \\
\text { grão em até } 20 \% \text { na ração sem } \\
\text { redução no desempenho animal. }\end{array}$ \\
\hline $\begin{array}{l}\text { Barton et al } \\
(2013)\end{array}$ & $\begin{array}{l}48 \text { bois da raça } \\
\text { Fleckvieh com PC inicial } \\
\text { médio }=232 \pm 29 \mathrm{~kg} \mathrm{e} \\
\text { idade inicial média }=7,4 \\
\pm \quad 0,5 \text { meses. } 12 \\
\text { animais/tratamento. } \\
\text { Período experimental } \\
\text { de } 266 \text { dias. }\end{array}$ & $\begin{array}{l}\text { Substituição parcial do grão de cevada } \\
\text { pelo glicerol não refinado. Foram } \\
\text { avaliadas quatro dietas: controle ( } 27,9 \% \\
\text { de cevada e } 0 \% \text { de glicerol), G5 ( } 21,4 \% \text { de } \\
\text { cevada e } 4,7 \% \text { de glicerol), G10 ( } 15 \% \text { de } \\
\text { cevada e } 9,3 \% \text { de glicerol) e CG10 }(27,9 \% \\
\text { de cevada e } 0 \% \text { de glicerol durante } 118 \\
\text { dias e } 15 \% \text { de cevada e } 9,3 \% \text { de glicerol } \\
\text { durante } 148 \text { dias). }\end{array}$ & $\begin{array}{l}\text { Não houve efeito }(\mathrm{P}>0,05) \text { de } \\
\text { tratamento sobre o CMS, PC final, } \\
\text { GPD, conversão alimentar, } \\
\text { características da carcaça e } \\
\text { qualidade da carne. Barton et al } \\
\text { (2013) concluíram que o glicerol } \\
\text { não refinado pode substituir a } \\
\text { cevada em } 10 \% \text { do total da MS da } \\
\text { ração em rações para bovinos de } \\
\text { corte em confinamento. }\end{array}$ \\
\hline $\begin{array}{l}\text { Hales et al } \\
(2013)\end{array}$ & $\begin{array}{l}50 \text { bezerros mestiços } \\
\text { com PC inicial médio = } \\
282 \pm 2 \mathrm{~kg} \text {. }\end{array}$ & $\begin{array}{l}\text { Substituição parcial do milho floculado } \\
\text { pelo glicerol não refinado. Foram } \\
\text { avaliadas cinco dietas: controle ( } 35,8 \% \text { de } \\
\text { milho floculado e } 0 \% \text { de glicerol), } 2,5 \% \\
\text { ( } 32,7 \% \text { de milho floculado e } 2,5 \% \text { de } \\
\text { glicerol), } 5 \%(29,5 \% \text { de milho floculado e } \\
5 \% \text { de glicerol), } 7,5 \% \text { ( } 26,4 \% \text { de milho }\end{array}$ & $\begin{array}{l}\text { Não houve resposta }(P>0,05) \text { entre } \\
\text { as dietas sobre o } C M S, P C \text { final e } \\
\text { eficiência alimentar. Houve efeito } \\
\text { quadrático }(P<0,05) \text { sobre o GPD, } \\
\text { tendo aumentado entre zero a } 7,5 \% \\
\text { de glicerol e diminuído entre } 7,5 \text { a } \\
10 \% \text {. A inclusão de } 7,5 \% \text { de glicerol } \\
\text { na dieta em substituição parcial ao }\end{array}$ \\
\hline
\end{tabular}




\begin{tabular}{|c|c|c|c|}
\hline & & $\begin{array}{l}\text { floculado e } 7,5 \% \text { de glicerol) e } 10 \% \text { ( } 23,3 \% \\
\text { de milho floculado e } 10 \% \text { de glicerol). }\end{array}$ & $\begin{array}{l}\text { milho floculado foi a que trouxe } \\
\text { maiores benefícios no desempenho } \\
\text { animal. }\end{array}$ \\
\hline $\begin{array}{l}\text { van Cleef et al } \\
\text { (2014) }\end{array}$ & $\begin{array}{l}30 \text { bois Nelore com PC } \\
\text { inicial médio }=227,7 \pm \\
23,8 \mathrm{~kg} \text { e idade inicial } \\
\text { média }=18 \text { meses. } 6 \\
\text { animais/tratamento. } 0 \\
\text { período experimental } \\
\text { foi de } 103 \text { dias. }\end{array}$ & $\begin{array}{l}\text { Substituição parcial do milho grão pelo } \\
\text { glicerol não refinado. Foram avaliadas } \\
\text { cinco dietas: controle ( } 35 \% \text { de milho grão } \\
\text { e } 0 \% \text { de glicerol), } 7,5 \% \text { ( } 25,5 \% \text { de milho } \\
\text { grão e } 7,5 \% \text { de glicerol), } 15 \% \text { ( } 18 \% \text { de } \\
\text { milho grão e } 15 \% \text { de glicerol), } 22,5 \% \\
\text { ( } 12,5 \% \text { de milho grão e } 22,5 \% \text { de glicerol) } \\
\text { e } 30 \% \text { ( } 5 \% \text { de milho grão e } 30 \% \text { de } \\
\text { glicerol). }\end{array}$ & $\begin{array}{l}\text { Não houve efeito }(P>0,05) \text { dos } \\
\text { níveis crescentes de glicerol na } \\
\text { dieta sobre o CMS, PC final, GPD, } \\
\text { conversão alimentar e } \\
\text { características da carcaça. Os } \\
\text { autores recomendaram a inclusão } \\
\text { de } 30 \% \text { de glicerol na dieta para } \\
\text { animais Nelore terminados em } \\
\text { confinamento. }\end{array}$ \\
\hline $\begin{array}{l}\text { Eiras et al } \\
(2014)\end{array}$ & $\begin{array}{l}40 \text { bois da raça Purunã } \\
\text { (1/4 Aberdeen Angus }+1 / 4 \\
\text { Caracu }+1 / 4 \text { Charolais }+1 / 4 \\
\text { Canchim }) \text { com PC inicial } \\
\text { médio }=209 \pm 33 \mathrm{~kg} \mathrm{e} \\
\text { idade inicial média }=8 \pm \\
0,9 \text { meses. } 10 \\
\text { animais/tratamento. } \\
\text { Período experimental } \\
\text { de } 240 \text { dias. }\end{array}$ & $\begin{array}{l}\text { Substituição parcial do milho grão pelo } \\
\text { glicerol não refinado. Foram avaliadas } \\
\text { quatro dietas: controle }(34,4 \% \text { de milho } \\
\text { grão e } 0 \% \text { de glicerol), } 6 \% \text { ( } 26,8 \% \text { de milho } \\
\text { grão e } 6 \% \text { de glicerol), } 12 \% \text { ( } 19,1 \% \text { de } \\
\text { milho grão e } 12 \% \text { de glicerol) e } 17,8 \% \\
\text { ( } 11,4 \% \text { de milho grão e } 17,8 \% \text { de glicerol). }\end{array}$ & $\begin{array}{l}\text { Não houve diferença }(P>0,05) \text { entre } \\
\text { os tratamentos sobre o } C M S \text {, } P C \\
\text { final e GPD. Houve aumento } \\
(P<0,05) \text { na eficiência alimentar } \\
\text { com o aumento do glicerol na dieta, } \\
\text { assim como aumento }(P<0,05) \text { na } \\
\text { digestibilidade aparente dos } \\
\text { nutrientes (à exceção do EE e FDN) } \\
\text { com a maior inclusão do glicerol na } \\
\text { dieta. Os autores recomendaram o } \\
\text { uso do glicerol não refinado em } \\
\text { rações para bovinos de corte em } \\
\text { confinamento quando houver } \\
\text { excesso desse subproduto no } \\
\text { mercado. }\end{array}$ \\
\hline $\begin{array}{l}\text { Egea et al } \\
\text { (2014) }\end{array}$ & $\begin{array}{l}306 \text { animais da raça } \\
\text { Limousin com PC inicial } \\
\text { médio }=273 \pm 43 \mathrm{~kg} \mathrm{e} \\
\text { idade inicial média }=7 \pm \\
1 \quad \text { meses. } 102 \\
\text { animais/tratamento. } \\
\text { Período experimental } \\
\text { de } 240 \text { dias. }\end{array}$ & $\begin{array}{l}\text { Substituição parcial do grão de cevada } \\
\text { pelo glicerol não refinado. Foram } \\
\text { avaliadas } 3 \text { dietas: controle ( } 42,7 \% \text { de } \\
\text { cevada e } 0 \% \text { de glicerol), } 2 \% \text { ( } 40,3 \% \text { de } \\
\text { cevada e } 2 \% \text { de glicerol) e } 4 \% \text { (38\% de } \\
\text { cevada e } 4 \% \text { de glicerol). }\end{array}$ & $\begin{array}{l}\text { Os níveis crescentes de glicerol na } \\
\text { dieta não influenciaram }(P>0,05) \text { o } \\
\text { CMS, PC final, GPD, eficiência } \\
\text { alimentar, características da } \\
\text { carcaça e qualidade da carne. Os } \\
\text { autores recomendaram a inclusão } \\
\text { de } 4 \% \text { de glicerol na dieta de } \\
\text { animais Limousin em confinamento. }\end{array}$ \\
\hline $\begin{array}{l}\text { Buttrey et al } \\
\text { (2015) }\end{array}$ & $\begin{array}{l}48 \text { bois mestiços com PC } \\
\text { inicial médio = 381 } \pm 7,6 \\
\mathrm{~kg} . \\
\text { animais/tratamento. }\end{array}$ & $\begin{array}{l}\text { Substituição parcial do milho floculado } \\
\text { pelo glicerol não refinado. Foram } \\
\text { avaliadas quatro dietas: controle ( } 72 \% \text { de } \\
\text { milho floculado e } 0 \% \text { de glicerol), } 2,5 \% \\
\text { ( } 69,42 \% \text { de milho floculado e } 2,5 \% \text { de } \\
\text { glicerol), } 5 \% \text { ( } 66,84 \% \text { de milho floculado e } \\
5 \% \text { de glicerol) e } 10 \% \text { ( } 61,86 \% \text { de milho } \\
\text { floculado e } 10 \% \text { de glicerol). }\end{array}$ & $\begin{array}{l}\text { Ausência de resposta }(P>0,05) \text { da } \\
\text { dieta sobre o CMS, PC final, GPD, } \\
\text { eficiência alimentar, peso final da } \\
\text { carcaça quente e rendimento de } \\
\text { carcaça. Houve redução linear } \\
(P<0,05) \text { da gordura subcutânea na } \\
12 \text { a costela com o aumento do } \\
\text { glicerol na dieta. Os autores } \\
\text { argumentaram que não houve } \\
\text { benefícios no desempenho animal } \\
\text { ao substituir parcialmente o milho } \\
\text { floculado pelo glicerol. }\end{array}$ \\
\hline Dias et al (2019) & $\begin{array}{l}28 \text { bois da raça Nelore } \\
\text { com PC inicial médio }= \\
441 \pm 40,2 \mathrm{~kg} \text { e idade } \\
\text { inicial média }=21,5 \pm 0,5 \\
\text { meses. } 14 \\
\text { animais/tratamento. } 0 \\
\text { período experimental } \\
\text { foi de } 98 \text { dias. }\end{array}$ & $\begin{array}{l}\text { Substituição parcial do sorgo grão pelo } \\
\text { glicerol não refinado. Foram avaliadas } \\
\text { duas dietas: controle }(33,5 \% \text { de sorgo } \\
\text { grão e } 0 \% \text { de glicerol) e glicerol ( } 18,5 \% \text { de } \\
\text { sorgo grão e } 15 \% \text { de glicerol). }\end{array}$ & $\begin{array}{l}\text { Não houve diferença }(P>0,05) \text { entre } \\
\text { as dietas sobre o CMS, conversão } \\
\text { alimentar, PC, peso da carcaça } \\
\text { quente e rendimento de carcaça. Os } \\
\text { autores afirmaram que o glicerol } \\
\text { não refinado pode substituir o sorgo } \\
\text { grão em } 15 \% \text { na ração de animais } \\
\text { Nelore em confinamento. }\end{array}$ \\
\hline
\end{tabular}

